\title{
Histórias de Insubordinações Criativas - narrativas de educadoras matemáticas
}

\author{
Stories of Creative Insubordination - Math Educators Narratives
}

\author{
Vanessa Crecci* \\ ORCID iD 0000-0001-6491-503X \\ Adair Mendes Nacarato** \\ ORCID iD 0000-0001-6724-2125
}

\begin{abstract}
Resumo
Este artigo tem como objetivo apresentar e discutir indícios de insubordinações criativas narradas por duas educadoras matemáticas que atuam como formadoras de professores e investigam os Anos Iniciais. A metodologia deste estudo ocorreu com base na pesquisa narrativa, que compreende um processo tridimensional de produção e análise dos textos de campo e de pesquisa, envolvendo temporalidade (diacronia), interações pessoais e sociais (sociabilidade) e o lugar (cenário) onde se situa o fenômeno a ser investigado e narrado. A partir da análise das entrevistas foram realizadas narrativas. Os resultados apontam que é possível vislumbrar que tais mulheres, educadoras matemáticas, optam pela realização de pesquisas conectadas ao cotidiano escolar, ambiente privilegiado de suas formações, constituindo posturas de insubordinação criativa. Isto significa dizer que, apesar das pressões institucionais pela realização de produções rápidas, as protagonistas deste estudo continuamente produzem um tipo de pesquisa narrativa, relacionada ao cotidiano escolar, que ocorre simultaneamente às transformações do campo científico e profissional da educação e do professor que ensina Matemática.
\end{abstract}

Palavras-chave: Professor que Ensina Matemática. Insubordinação Criativa. Pesquisa Narrativa.

\begin{abstract}
This article aims to present and discuss evidence of creative insubordination narrated by two mathematical educators who act as teacher educators and investigate the early school years. The methodology of this study was based on a narrative inquiry, which comprises a three-dimensional process of production and analysis of field and research texts, involving temporality (diachrony), personal and social interactions (sociability), and the place where the phenomenon to be investigated and narrated is located. We gathered the narratives from the analysis of the interviews were carried out narratives. The results show that it is possible to envisage that these women, mathematical educators, choose to carry out research connected to the daily school life, privileged environment of their professional development, constituting positions of creative insubordination. This means that, despite the institutional pressures by conducting quick researches, the protagonists of this study continually produce a kind of narrative research, related to school daily life, that occur in the same time of the transformations of the scientific and professional field of education and math teacher field in Brazil.
\end{abstract}

Keywords: Math teacher. Creative Insubordination. Narrative research.

* Doutora em Educação (Educação Matemática) pela Universidade Estadual de Campinas (UNICAMP). Consultora acadêmica e professora colaboradora do Mestrado Profissional em Educação Escolar da Faculdade de Educação da Unicamp, Campinas, SP, Brasil. Endereço para correspondência: Av. Júlio de Mesquita, 1019 Cambuí, Campinas, SP, Brasil, CEP: 13025-061. E-mail: vancrecci@gmail.com.

${ }^{* *}$ Doutora em Educação (Educação Matemática) pela Universidade Estadual de Campinas (UNICAMP). Docente do Programa de Pós-Graduação Stricto Sensu em Educação da Universidade São Francisco (USF), Itatiba, SP, Brasil. Endereço para correspondência: Rua Zerillo Pereira Lopes, 651, casa 15, Alto Taquaral, Campinas, SP, Brasil, CEP: 13087-757. E-mail: adamn@ @erra.com.br. 


\section{Introdução}

O conceito de insubordinação criativa vem ganhando espaço no campo do professor que ensina Matemática e tem sido utilizado por investigações que se centram nas práticas docentes e de formação desses profissionais. A partir do momento em que nos deparamos com este questionamento das colegas: "Por que considerar a insubordinação criativa para redimensionar as práticas dos educadores matemáticos?" (D’AMBROSIO; LOPES, 2015a, p. 03), temos refletido sobre diversas posturas de insubordinação criativa assumidas diante de burocratizações e normatizações do contexto acadêmico. E assim, problematizamos: quais são os modos de insubordinação que educadoras matemáticas mobilizam ao longo de suas trajetórias? Veremos, nas narrativas e em suas análises, que a insubordinação criativa vem sendo uma constante no cotidiano de tantas outras colegas, como forma de resistência e de produção de uma pesquisa conectada ao cotidiano escolar.

Dito isso, gostaríamos de compreender como tais posturas culminam em uma pesquisa realizada com profícuas proximidades com o ambiente escolar. Optamos por entrevistar seis educadoras matemáticas que atuam como formadoras de professores, têm como foco de pesquisa os anos iniciais da educação básica e a formação de professoras desse nível de ensino e participam de um grupo interinstitucional de estudos e pesquisa.

Neste artigo, analisamos duas dessas entrevistas, textualizadas em forma de narrativa. Nossa metodologia da pesquisa narrativa fundamenta-se em Clandinin e Connelly (2011). Inicialmente realizamos uma revisão do conceito de insubordinação criativa, com base em D’Ambrosio e Lopes (2014, 2015a, 2015b), para, então, narrar as trajetórias dessas duas educadoras matemáticas, os modos como se projetam em um campo científico e profissional e como assumem posturas de insubordinação criativa. Ao final, tecemos considerações sobre as narrativas produzidas e o conceito abordado.

\section{Insubordinação criativa e a pesquisa conectada com a escola}

Em nosso cotidiano nas universidades, volta e meia nos deparamos com a necessidade de balancear obrigações profissionais e as crenças que orientam as opções acadêmicas de estudos que realizamos, muitas vezes orientadas por nossas trajetórias de vidas. Beatriz D'Ambrosio e Celi Espasandin Lopes, em uma variedade de textos publicados entre 2014 e 2015, trazem ao contexto brasileiro o conceito de Insubordinação Criativa. Segundo as autoras, tal conceito tem sua origem em 1981, em um relatório sobre um estudo etnográfico realizado 
com diretores de escolas de Chicago, em que se discutiram as ações de insubordinação criativa como um recurso diante da burocracia educacional (D'AMBROSIO; LOPES, 2015a).

Segundo as autoras, aquele estudo revelou que os gestores tomam decisões que não atendem às expectativas de instâncias superiores, quando percebem "a necessidade de desobedecer ordens em prol da melhoria e do bem-estar da comunidade educacional de modo a preservar princípios éticos, morais e de justiça social” (D’AMBROSIO; LOPES, 2015a, p. 02). A partir desse movimento, as autoras começaram a indagar "por que considerar a insubordinação criativa para redimensionar as práticas dos educadores matemáticos?" (D’AMBROSIO; LOPES, 2015a, p. 03).

Em outro estudo, D’Ambrosio e Lopes (2015b) analisam narrativas de educadoras matemáticas, professoras da Educação Infantil, destacando que "o ato de se desvencilhar da autoridade do currículo, bem como de algumas teorias que delimitam o que a criança é capaz de elaborar, permitiu a elas eleger o aluno como protagonista no processo de ensino e aprendizagem” (D’AMBROSIO; LOPES, 2015b, p. 04). Em síntese, concluem que, para as educadoras tornarem-se profissionais subversivamente responsáveis:

[...] foi necessário que assumissem ações complexas e não lineares, determinando um fazer pedagógico na educação de infância que não pode ser analisado somente do ponto de vista instrumental, sem percepção do envolvimento da professora e das consequências para sua subjetividade (D’AMBRÓSIO; LOPES, 2015b, p. 11).

Posturas insubordinadas estão relacionadas às crenças que mobilizamos em nosso trabalho diário, pois se conectam a um tipo de conhecimento profissional construído ao longo de nossas carreiras, que "envolve elementos como origem social, política e cultural, bem como aspectos de foro pessoal e contextual” (D’AMBROSIO; LOPES, 2015b, p. 06). Em síntese, segundo as autoras, via de regra "o professor e o pesquisador se deparam com uma estrutura escolar ou universitária imersa em profundo controle burocrático e tecnocrático, limitante e condicionante da ação educativa e investigativa" (D’AMBROSIO; LOPES, 2015b, p. 06).

Nesse cenário, segundo as autoras, as manifestações de insubordinações criativas dos pesquisadores em Educação Matemática podem ser consideradas pelos questionamentos feitos em relação aos posicionamentos metodológicos rígidos; à perspectiva avaliativa da produção do outro; às incoerências entre práticas e relatos de pesquisas; à ação política contraditória ao discurso; aos critérios aleatórios utilizados para avaliar a qualidade da produção científica; à distribuição de verbas para produção científica; à avaliação quantitativa das publicações; à posição do pesquisador como intelectual (dono do saber) nos relacionamentos entre professor e aluno e entre pesquisador e sujeito (D’AMBROSIO; LOPES, 2015a). Tais ponderações, porém, necessitam ser acompanhadas de uma rememoração. Vamos a ela: 
No início da constituição do campo da formação de professores no Brasil, sabemos que as pesquisas em Educação, seguindo uma tendência internacional, poderiam ser categorizadas em dois paradigmas: 1) com foco no processo-produto, envolvendo pesquisas que correlacionavam o comportamento dos professores com o desempenho dos estudantes; e 2) com ênfase no aspecto qualitativo ou interpretativo, contemplando pesquisas provenientes (ou fortemente vinculadas aos campos) da sociologia, da antropologia e da linguística, que se propunham a descrever detalhadamente as práticas do ensino e seus contextos. Ambos os paradigmas tornavam os professores invisíveis como criadores de conhecimentos sobre o ensino e a aprendizagem na prática escolar (COCHRAN-SMITH; LYTLE, 1990).

No Brasil, foi apenas a partir do final da década de 1990 e do início dos anos 2000 que se iniciou um estreitamento da relação entre a comunidade científica de educadores matemáticos e as comunidades escolares, principalmente com os grupos colaborativos, as comunidades de prática ou de investigação. Nesse cenário também ocorreu uma mudança no paradigma do que compreendemos como pesquisa do professor: com o reconhecimento, pelas comunidades acadêmicas, da necessidade de maior articulação e interlocução com as comunidades escolares, passou-se da pesquisa sobre o professor para a pesquisa com o professor e, com os programas de formação na escola, esse processo de estreitamento pode ter sido influenciado por políticas como o Programa Institucional de Bolsas de Iniciação à Docência (PIBID) e o Observatório da Educação (Obeduc).

A pesquisa e/ou a investigação de professores em espaços coletivos, como nas comunidades investigativas, começou a ser valorizada a partir da década de 90 (COCHRANSMITH; LYTLE, 1993). Grupos, então, surgiram, congregando professores da escola básica e acadêmicos interessados em investigar os modos de ensinar e de aprender na escola básica. É possível que tal fato tenha sido decorrente da mudança de concepção das práticas de formação de professores, tendo em vista a relação entre formação acadêmica e prática profissional.

Fiorentini e Lorenzato (2006) destacam a inserção crescente de professores que ensinam na escola básica em grupos acadêmicos de pesquisa, a maioria ligados à Pós-Graduação stricto sensu. Podemos dizer que as protagonistas deste estudo fizeram parte dessa geração que, na década inicial dos anos 2000, frequentava o espaço fronteiriço entre a universidade e a escola. Atualmente, talvez possa se afirmar que, no contexto da pesquisa do professor que ensina matemática, entre esses professores estão algumas das educadoras que partilham das transformações de um campo que começa a ser mais aberto para as vozes da escola.

Outro fator que marcou esse período foi o crescimento dos programas de pós-graduação e o surgimento dos mestrados profissionais. É nesse cenário que, inspirados nas experiências 
de grupos já existentes e em razão, sobretudo, do aumento da presença de professores da escola básica na universidade e de formadores na escola básica, têm surgido, cada vez mais, grupos com a participação de professores, formadores de professores, pesquisadores e, até mesmo, futuros professores. Desse modo, mais do que estabelecer parcerias com acadêmicos, os professores passam a realizar estudos sobre sua prática, ocupando espaço na academia e dando visibilidade ao seu trabalho.

Nesse cenário ocorreram o desenvolvimento profissional e a constituição das duas educadoras, pesquisadoras experientes do campo científico do professor que ensina Matemática, que têm suas histórias narradas neste artigo e cujas trajetórias podem ser consideradas de insubordinação criativa. Conhecer as narrativas de educadoras matemáticas participantes de uma comunidade interinstitucional pode ser um modo profícuo de compreender a insubordinação responsável como resposta a tradições constituídas de ambientes acadêmicos.

\section{A pesquisa narrativa como caminho metodológico}

A metodologia deste estudo terá como base a pesquisa narrativa, que compreende um processo tridimensional de produção e análise dos textos de campo e de pesquisa, envolvendo temporalidade (diacronia), interações pessoais e sociais (sociabilidade) e o lugar (cenário) onde se situa o fenômeno a ser investigado e narrado.

Clandinin e Connelly (2011) argumentam que os acontecimentos estudados estão em transição temporal, e os autores têm como questão central a temporalidade, uma vez que têm como certo que localizar as coisas no tempo é a forma de pensar sobre elas. Apontam, ainda, que: "quando vemos um evento, pensamos sobre ele não como algo que aconteceu naquele momento, mas sim como uma expressão de algo acontecendo ao longo do tempo" (CLANDININ; CONNELLY, 2011, p. 63). Nesta pesquisa, optamos pela compreensão diacrônica do tempo; assim, acontecimentos serão compreendidos ao longo do tempo.

Assim como a temporalidade, a sociabilidade também deve permear as narrativas dessa perspectiva. Para Clandinin e Huber (2010, p. 05), pesquisadores narrativos atendem simultaneamente às condições pessoais e sociais. Por condições pessoais, elas compreendem os sentimentos, as esperanças, os desejos, as reações estéticas e os dispositivos morais dos participantes. E, por "sociabilidade", as autoras se referem aos contextos nos quais as experiências pessoais são constituídas, compreendidos em termos de narrativas culturais, sociais, institucionais e linguísticas.

Clandinin e Connelly (2011) definiram lugar como o local específico e concreto, físico 
e de fronteiras topológicas, locais e sequência de locais onde a pesquisa e eventos acontecem. Pesquisadores narrativos possuem suas identidades inexoravelmente conectadas com as experiências constituídas em determinados locais e com as histórias que são contadas em locais específicos ou com as histórias que contamos sobre as experiências que vivemos em determinados contextos (CLANDININ; HUBER, 2010). O ponto de entrecruzamento das experiências dos participantes desta pesquisa é uma comunidade acadêmica interinstitucional, da qual as autoras deste texto fazem parte.

Na perspectiva da pesquisa narrativa, textos de campo podem ter variadas fontes de dados, para que possamos "falar sobre o que é considerado dados de pesquisa" (CLANDININ; CONNELLY, 2011, p. 143). Os dados das pesquisas narrativas podem ser notas de campo da experiência, registros em diário, transcrições de entrevistas, observações, relatos de histórias, cartas, autobiografias e documentos, como planos de aula e boletins informativos, anotações pessoais etc. No presente estudo, os textos de campo - que, na perspectiva desses autores, produzem os textos de pesquisa - foram constituídos por entrevistas narrativas. Ou seja, os textos de pesquisa foram constituídos pelas textualizações das narrativas de histórias de vida das participantes da pesquisa.

Na primeira fase do trabalho de campo, entre os meses de novembro e dezembro de 2016, foram realizadas seis entrevistas com educadoras matemáticas que investigam os Anos Iniciais e que participam da citada comunidade. Mediante convite das participantes, as entrevistas aconteceram em suas próprias casas, e nosso objetivo era conhecer aspectos relacionados às trajetórias que as seis professoras percorreram no campo do professor que ensina Matemática.

Antes de realizar as entrevistas, a primeira autora deste texto realizou uma pesquisa sobre a trajetória de cada uma das entrevistadas, através da consulta de materiais publicados, como livros e artigos. O trabalho com esse material resultou em seis diferentes roteiros, que conduziram as primeiras entrevistas, a partir das quais se produziram as narrativas, posteriormente retomadas, em uma segunda entrevista com as participantes do estudo. Dessa outra conversa resultou uma nova versão das narrativas, agora mais coesas e mais ricas em detalhes.

Neste artigo, trazemos duas dessas narrativas em versões reduzidas, em decorrência do limite de páginas; nelas analisamos as histórias de vida das professoras no espaço tridimensional da pesquisa narrativa que, conforme já citado, envolve temporalidade (diacronia), interações pessoais e sociais (sociabilidade) e o lugar (cenário). Portanto, ao textualizar as entrevistas, tivemos como fios condutores esses três elementos que são centrais 
no processo da pesquisa narrativa baseada em Clandinin e Connelly (2011). Com isso, nossa intenção foi apresentar, através das histórias de vida dessas participantes, indícios de que elas optaram pela realização de pesquisas conectadas ao cotidiano escolar, ambiente privilegiado de suas formações, constituindo posturas de insubordinação criativa.

\section{Duas histórias de insubordinações criativas}

Revisadas pelas duas protagonistas que tiveram suas histórias contadas, estas narrativas seguintes apresentam aspectos de sua biografia e indícios de posturas de insubordinação criativa. $\mathrm{O}$ comitê de ética da instituição à qual a pesquisa está vinculada considerou que o não anonimato se justifica pelo fato de as participantes do estudo terem acesso ao conteúdo do que viria a ser publicado.

\section{Narrativa de Regina}

Regina Célia Grando é licenciada pela Universidade Estadual de Campinas (Unicamp). Possui o título de mestre e doutora pela mesma universidade. Atualmente é professora titular de uma universidade federal. Sua atuação tem tido como ênfase a prática pedagógica e a formação docente. Seus principais temas de investigação são: formação de professores que ensinam Matemática, desenvolvimento profissional docente, professor que ensina Matemática e infância, jogo e resolução de problemas.

A professora começou a entrevista enfatizando a importância de sua família em sua trajetória profissional. Ela é a sexta filha de sete irmãos. Contou com entusiasmo que seu pai foi professor de Português em escolas tradicionais da cidade de Campinas. Relatou também o fato de duas irmãs serem professoras de Matemática. A pesquisadora, então, passou a contar sobre a sua vontade de ser professora e da familiarização com a área desde sua infância: "eu sempre gostei de ser professora, sempre quis ser professora”.

Continuou enfatizando que o ambiente de sua casa era um local profícuo para sua constituição profissional; destacou se lembrar de seu pai participando de passeatas contra as políticas do governo Maluf em meados da década de 80. Destaca que, naquelas ocasiões, “eu também participava com ele, eu tinha catorze ou quinze anos". Continuou, então, recordando como escolheu ser professora da matemática:

[...] essa história de educação era muito viva na minha casa, então, com oito anos de idade, eu disse que eu iria ser professora de matemática, eu achava lindo minhas irmãs mexerem com 
compasso (Entrevista com Regina, 2017).

Regina realizou a sua escolarização em um tradicional colégio localizado na cidade de Campinas. Revelou que a disciplina de que mais gostava era Matemática e também enfatizou sua postura autêntica. Lembrou-se, assim, que durante as aulas de Matemática: "sempre me coloquei, falava e questionava” (Entrevista com Regina, 2017).

Aos 17 anos de idade ingressou no curso superior de Matemática na Unicamp. A ocasião foi bastante celebrada em sua família. E Regina passou a narrar sobre sua trajetória no Instituto de Matemática, Estatística e Computação Científica (IMECC). Em meio a tantas disciplinas de Matemática geral, a partir do encontro com a professora Beatriz D’Ambrosio, ocorrido em $1987^{1}$, Regina se aproximou do campo da Educação Matemática. Foi, então, que, ao assistir a uma palestra de Bia sobre o campo, percebeu: "é isso que eu quero fazer, eu quero ser professora de matemática” (Entrevista com Regina, 2017).

Em seguida, a entrevistada deu destaque para o início das atividades acadêmicas, enfatizando, sobretudo, como a parceria com Bia foi muito importante em sua formação. A postura colaborativa de Bia na condição de orientadora de iniciação científica é, então, narrada pela entrevistada:

A Bia é muito colaborativa. Estava no auge a discussão de uma nova proposta curricular do estado de São Paulo. Não existia muita coisa sobre esse material que era em formato de jornal. Ela, então, falou: "Pronto, então, vamos começar a estudar a proposta". Sentávamos, líamos juntas atividade por atividade e discutíamos. Ela já fazia a análise, e, depois, mandava o jornal com as análises. Depois, uma escola também mandou material perguntando como poderia ser usado. Nós sentávamos e criávamos (entrevista Entrevista com Regina, ano2017).

Entre os anos de 1987 e 1988, o vínculo com a professora Beatriz D’Ambrosio estreitouse com a realização de um projeto de iniciação cientifica com jogos em aulas de Matemática. Regina narra o início desses estudos, destacando que a docente a incentivou a trilhar o caminho da pós-graduação no campo da Educação Matemática. Sobre isso, também, destaca que o vínculo com Bia lhe possibilitou lançar-se na realização de palestras, eventos acadêmicos e formação de professores:

A partir de uma indicação da Bia, a primeira palestra que eu fiz, eu me lembro que foi para cem professores, no Espírito Santo, na Universidade Federal do Espírito Santo. Eu, Valéria e a Bia. Aí, em 89, também realizamos um minicurso de jogos no primeiro Encontro Paulista de Educação Matemática (Entrevista com Regina, 2017).

Lembra-se, então, do papel de mentora que Bia exercia, quando ela questionava sua própria capacidade:

E eu dizia assim: "Bia, eu só tenho dezoito anos, o que eu vou falar na frente dos

1 Ao longo da entrevista, Regina se refere à professora Beatriz D'Ambrosio como Bia. 
professores?". Ela falou assim: "Você vai chegar e falar assim: eu sou aluna de iniciação científica, eu venho trabalhando com jogos, então, eu vou ensinar para vocês sobre os jogos e, vocês, me ensinam sobre a escola” (Entrevista com Regina, ano).

No início da década de 90, Bia foi realizar o doutorado nos Estados Unidos, na Universidade de Indiana. Nessa ocasião, Regina estava concluindo a graduação, e muitos dos materiais de Educação Matemática Bia deixou para ela. Ao narrar essa situação, Regina revelou que as duas mantiveram troca frequente de cartas. E retomou o conteúdo de uma delas, na qual revelava seu interesse em continuar estudando jogos.

[...] eu contava um pouco sobre o IMECC, coisas do dia a dia, contava para ela: "Bia, eu vou fazer um projeto de pesquisa para fazer mestrado" [...]. Nessa carta, inclusive, eu falo assim: "eu penso em trabalhar com os jogos. Você tem algum material para me mandar?" (Entrevista com Regina, 2017).

A orientadora de iniciação científica, naquele momento aconselhou Regina a continuar seus estudos na Faculdade de Educação. Bia já havia apresentado Regina ao professor Sérgio Lorenzato, que passou a ser outro incentivador e a indicá-la para ministrar cursos para professores em outros estados do Brasil.

Durante a entrevista, Regina, em diversos momentos, demonstrou gratidão pelos diversos convites que recebeu, valorizando a confiança depositada em seus trabalhos. Reconhece que esses incentivos favoreceram seu desenvolvimento acadêmico, profissional e pessoal.

Sobre o início da docência na escola, Regina se formou em Matemática em 1990. No ano de 1991, lançou-se como professora na escola pública, tendo sido coordenadora da área de Matemática, Física e Química. Naquele momento era desenvolvido, na Rede Estadual de São Paulo, o projeto de Escola Padrão. Em colaboração com outros professores, a partir da sugestão de um colega, Regina e os professores da escola começaram a planejar aulas. Sobre esse período, recorda que

[...] dava aula na escola e muita palestra. Eu entrei em 91 na escola pública, na época tinha que escolher os coordenadores de área, eu fui coordenadora de área que incluía matemática, física e química [...]. Na minha cabeça, eu tinha que levar textos para os professores, aí, o Fausto - um colega da Unicamp - virou e falou assim: "Regina, e se elaborarmos aulas juntos", ele que deu a ideia, eu falei: "Nossa, Fausto, que ideia boa", aí, começamos a fazer isso (Entrevista com Regina, 2017).

Foi em 1992 que iniciou o mestrado acadêmico, na Faculdade de Educação da Unicamp, sob a orientação do professor Sérgio Lorenzato. Regina, então, aprofundava o estudo sobre jogos iniciado em parceria com Bia. Esse tema também foi desenvolvido em sua tese de doutorado, defendida em 2000. Cabe destacar que sua tese foi destaque como um dos trabalhos mais consultados na Biblioteca da Faculdade de Educação da Unicamp. 
Em 1995, Regina então começou a trabalhar em uma outra escola na cidade de Campinas, com metodologia alternativa, instituição pela qual possui grande admiração:

[ ...] eu lembro do primeiro dia que eu cheguei para dar uma aula de jogo, era na sétima série, eu falei: "hoje nós vamos trabalhar com jogo". Logo em seguida, os estudantes se organizaram, eles olharam para mim, eu falei: "gente, eu estou no paraíso". Eu digo que lá é pós-graduação de dar aula, porque os alunos são muito críticos, questionadores. O grupo de pais também é muito interessante. Eu considero que continuei me formando ali. Tinha um grupo muito bom de professores [...] A formação que tínhamos dentro daquela escola era bárbara, entendeu? (Entrevista com Regina, 2017).

Dando continuidade ao trabalho realizado na escola e às parcerias que estabeleceu com educadores matemáticos, em 1996, Regina ingressou no doutorado, na Faculdade de Educação, da Unicamp. A temática de sua pesquisa foi o jogo no ensino da Matemática. Sua intenção fora investigar "o movimento do pensamento matemático dos alunos enquanto jogavam". Os participantes da pesquisa foram oito alunos da 6. ${ }^{\text {a }}$ série (11/12 anos) do Ensino Fundamental, realizando atividades de intervenção pedagógica com dois jogos matemáticos. Embora a pesquisadora-professora não assuma esse estudo como uma pesquisa da própria prática, Regina realizou esse estudo na escola em que atuava.

Em 2000 iniciou a carreira docente no Ensino Superior, ano em que se casou. No final desse mesmo ano, ingressou em uma universidade no interior de São Paulo, na cidade de Batatais, em São Paulo, para ministrar disciplinas de Geometria. Entretanto, antes de começar a lecionar, o pró-reitor dessa mesma instituição fez uma ligação para informá-la que ela deveria ocupar o cargo de coordenadora do curso de Matemática. Regina, então, aceitou a função e se lançou nesse outro desafio. A partir de então, ela começou a conhecer a legislação e a notar o distanciamento entre parte dos discursos acadêmicos e a legislação que necessitava ser implantada mediante a publicação das diretrizes de formação de professores de 2002. Segundo ela:

eu fiquei interessada naquela terminologia que dizia sobre o professor investigativo $e$ pesquisador. Explicava, também, para meus colegas sobre as quatrocentas horas de estágio e as quatrocentas horas de prática como componente curricular e não como disciplina (Entrevista com Regina, 2017).

No ano de 2002, a professora passou a atuar como assessora de escolas particulares, na cidade de Franca, em São Paulo. Ela destacou que aquele foi um momento de muita importância para seu desenvolvimento profissional e bastante aproximação com a Educação Infantil e os Anos Iniciais. De acordo com ela,

foi nessa escola que me aproximei dos currículos de educação infantil e dos anos iniciais. Ali começou outra grande experiência que já tinha começado quando eu dei aula de didática da matemática na pedagogia (Entrevista com Regina, 2017). 
No ano seguinte, prestou concurso para uma outra universidade privada, na qual se estabeleceu por mais de 15 anos. Nessa instituição coordenou diversos grupos de estudos e pesquisas com professores da escola básica e alunos da pós-graduação. Atuou nos cursos de Licenciatura em Matemática e Pedagogia, bem como no Programa de Pós-Graduação em Educação, tendo orientado estudantes de mestrado e doutorado, além de iniciação científica, com uma significativa produção, boa parte em parceria com professores da Educação Básica.

Ao longo de sua entrevista, notamos a imbricação entre teoria e prática em sua trajetória acadêmica e profissional. As escolhas profissionais e acadêmicas da entrevistada estão relacionadas ao campo escolar. Ao final da entrevista, Regina destaca seu reencontro com Bia e a vontade de continuar investigando a insubordinação criativa nas crianças.

Eu fiquei um tempo afastada da Bia, pelo fato dela ter ido morar nos EUA. Em 1996, encontrei com a Bia na Espanha. Foi uma delícia! Em 2003, quando ela vem para o CIAEM - Blumenau, eu estava grávida e reencontro a Bia novamente. A partir dai começamos a trocar de novo mensagem por e-mail. A Bia sempre foi uma pessoa da prática, a Bia tinha uma coisa muito interessante: para ela, não existe hierarquia! Você pode estar falando a maior besteira, mas é como você pensa. Então, ela é uma pessoa que problematizava. Ela deixava você fazer o que você tinha de melhor, então, ela sempre deixou o outro crescer muito. Ela não se importava se outro aparecesse mais que ela. Ai, começamos a conversar. Um pouco antes da Bia falecer, junto com a Celi, começamos a discutir sobre insubordinações criativas. Eu conheci esse material por elas. Um dia, eu falei: "mas, será que só o pesquisador e o professor? As crianças também têm práticas insubordinadas” (Entrevista com Regina, 2017).

Nos últimos doze anos, Regina tem coordenado e participado de projetos que envolvem parceria com profissionais da escola. Podemos destacar, ao menos, dois projetos que foram nessa direção. Entre 2012 e 2014, destaca-se o projeto realizado no contexto de parceria entre universidade-escola, em colaboração com outros professores da instituição em que Regina atuava na ocasião. O objetivo foi investigar quais saberes são produzidos e mobilizados em um grupo colaborativo, quando se toma o estudo de aulas videogravadas como objeto de investigação, e identificar e analisar os discursos matemáticos dos alunos da Educação Básica.

O referencial metodológico desse projeto foi a pesquisa colaborativa. Nesse caso, a parceria entre os participantes do grupo na análise de aulas videogravadas pôde contribuir para, entre outros aspectos, identificar as possíveis aprendizagens sobre a Matemática escolar por professores inseridos em um contexto de colaboração e de investigação; e compreender os saberes docentes produzidos e (re)significados nos momentos em que o grupo prepara tarefas para a sala de aula, analisa os vídeos produzidos em suas salas de aula e produz sistematizações por meio de narrativas. Os professores participantes do projeto narraram, eles próprios, os acontecidos no contexto escolar, sendo eles os protagonistas e quem desvela suas aprendizagens, dando a ver o desenvolvimento profissional. 
Outra pesquisa desenvolvida no contexto da parceria universidade-escola, coordenada por Regina entre 2013 e 2015, teve como objetivo geral investigar, por meio de um trabalho colaborativo com professores da Educação Básica, as práticas de letramentos escolares - mais especificamente, o letramento matemático - e as práticas de formação docente de professores que ensinam Matemática. Os professores envolvidos no projeto, em parceria com professores formadores da Universidade, analisaram os dados disponibilizados pelo censo escolar, que fornece informações sobre os estabelecimentos de ensino envolvidos no projeto e o rendimento escolar dos alunos no decorrer dos anos. Também foi analisado o desempenho dos alunos na Provinha Brasil de Matemática.

O foco do projeto foi centrado no letramento matemático das crianças no ciclo de alfabetização, por meio da parceria entre professores da escola pública e professores da Universidade. Foram elaboradas tarefas a serem desenvolvidas em sala de aula. Seu desenvolvimento foi videogravado, e a análise das atividades se realizou de forma conjunta com professores da escola e professores da Universidade. Nesse projeto, em especial, os professores da escola foram considerados multiplicadores do trabalho pedagógico.

\section{Narrativa de Cármen}

Carmen Lucia Brancaglion Passos é licenciada em Matemática pela Pontifícia Universidade Católica de Campinas (PUCCamp). Graduou-se em 1977, tendo realizado mestrado e doutorado na Unicamp, na Faculdade de Educação, entre 1995 e 2000. No exterior, realizou seu pós-doutorado na Faculdade de Ciências da Universidade de Lisboa, concluído no ano de 2008.

Há 16 anos é professora de uma universidade federal na qual atua e coordena projetos de extensão ligados ao ensino de Matemática na Educação Básica, em especial, nos Anos Iniciais. Exerceu dois mandatos como Coordenadora do Programa de Pós-Graduação em Educação dessa instituição, tendo atuação expressiva no Fórum de Coordenadores de Programas de Pós-Graduação em Educação (FORPRED), sobretudo, nas recentes discussões sobre o mestrado profissional da área.

No contexto do programa de pós-graduação, investiga e orienta pesquisas de mestrado e doutorado sobre a formação e o desenvolvimento profissional de professores que ensinam Matemática e tem adotado como metodologia de pesquisa as narrativas de formação de professores que ensinam Matemática. Desde 2011, é bolsista produtividade do CNPq.

Das coisas que o currículo Lattes não nos conta: nascida e criada em Campinas, primeira 
filha de uma mãe costureira e um pai operário, cresceu na região do Parque Industrial, bairro operário da cidade. Inicialmente, Cármen foi questionada sobre a razão pela qual havia escolhido ser professora e destacou que não tinha ideia de que poderia ser professora, ao cursar Matemática.

[...] mesmo durante o curso de matemática, não me via sendo professora de matemática. Desde que eu fui para o ensino médio, isto é, atual ensino médio, eu me preparei para começar a trabalhar em outras profissões. Então, na sétima série, hoje oitavo ano, a minha mãe já nos colocou para aprender datilografia e se preparar para começar a trabalhar quando começasse o ensino médio, foi o que aconteceu (Entrevista com Cármen, 2017).

Ao longo da entrevista, com nostalgia, Cármen se lembrou das motivações de seus pais para que ela e seus irmãos estudassem. Em um tempo em que educação não era um direito assegurado, o incentivo e a valorização de seus pais eram tamanhos que sua mãe prestava serviços como costureira para uma escola confessional para que seus filhos tivessem bolsa de estudo para cursar o primário.

Já na década de 1970, Cármen iniciou o que corresponderia ao Ensino Médio. No período noturno de uma escola pública tradicional na cidade, ela optou por cursar o último ano voltado para o campo das exatas.

O ensino deixa de ser científico, clássico e normal. Havia dois anos de básico para todo mundo igual, ai no terceiro ano você poderia fazer opção para ciências humanas, para o científico, para as exatas, ou para as biológicas. Eu fiz para as exatas. Então, eu tive desenho geométrico, matemática, física, química, mais do que quem tinha feito opção por biológicas (Entrevista com Cármen, 2017).

Em seguida a esse histórico sobre sua escolarização, Cármen narrou a relação que seus pais estabeleciam com a escolarização dos filhos. Então, lembrou-se de que, para seus pais:

[...] o estudo era a única opção para não ser operário, para ter um trabalho menos braçal... Era a opção a qual fomos apresentados. E ai, foi um incentivo constante para a escola, para estudar e estudar. Mesmo precisando trabalhar, tinha essa coisa de estudar. Nunca foi "seja o melhor da aula", mas os incentivos foram muitos (Entrevista com Cármen, 2017).

Quando Cármen relatou sobre a relação de sua família com sua escolarização, descreveu como era constituída sua família e narrou um acontecimento trágico, que viria a mudar o rumo de sua história. Revelou o momento em que sua vida mudou, após o falecimento de um irmão, pois, naquela altura, ela havia concluído o curso de Licenciatura na PUCCampinas e estava trabalhando, concursada, na Petrobras, desde a conclusão do Ensino Médio. Com essa intercorrência na família, Cármen começou a questionar sua rotina, o quanto valeria a pena continuar trabalhando em um ambiente no qual não havia flexibilização de horário e nem políticas efetivas de incentivo à maternidade. Foi, então, que, grávida de seu primeiro filho, ingressou na rede estadual. 
Aí, o que acontece? Eu fui fazer matemática porque eu gostava, então eu entrei na faculdade e entrei ao mesmo tempo na Petrobras. Quando eu terminei meu curso de matemática, em 77, o meu irmão faleceu no final do ano. Ai então eu mudo a minha perspectiva, do contrário, talvez eu tivesse aposentado na Petrobras... Quando o meu irmão faleceu, eu fiz uma mudança na minha estrutura de vida, e isso incluiu ser professora, pois cuidava do Fábio, meu filho, de dia; e trabalhava à noite (Entrevista com Cármen, 2017).

Naquele momento, Cármen se lembra de que seu salário de jornada parcial na rede estadual era um sétimo do que recebia na Petrobras. Inicialmente, durante um ano, a professora atuou na cidade de Franco da Rocha, cidade próxima à região de Jundiaí, interior de São Paulo. Naquela época começou a compartilhar carona com amigos que também se tornaram colegas de Universidade. Foi também nessas caronas que a professora começou a ter seus primeiros contatos com os estudos pós-graduados.

Se, por um lado, havia falta de incentivo salarial na rede estadual, as conversas com professores que cursavam mestrado ou doutorado, por outro, foram essenciais para que a professora decidisse investir na profissão. Em uma primeira tentativa se deparou com uma perspectiva de ensino de Matemática, baseada na ideia de que saber mais Matemática é suficiente para ensinar melhor.

[...] pensei "bom, eu sou professora, eu vou me aperfeiçoar como professora"... Fui na Unicamp em 78, começo de 78, para saber como que era o curso de especialização, porque eu achava que pra eu ser professora, precisava agora estudar mais, o que eu tinha estudado não era pensando em ser professora. Mas aí, quando eu chego lá na Matemática com uma colega, eles falam assim: "mas você estudou na PUC? Então, primeiro tem que fazer especialização".... Naquele tempo, não imaginava que na faculdade de educação também estudavam matemática (Entrevista com Cármen, 2017).

Após um ano atuando em Franco da Rocha, Cármen pediu remoção e foi lecionar em Hortolândia. Seu interesse por se especializar foi aumentando. Com seu colega Lorenzo, professor da área de Português em sua escola e mestrando do Instituto de Estudos da Linguagem (IEL), da Unicamp, começou a estudar aspectos pedagógicos sobre sua atuação no âmbito da escola. Daquele tempo, recorda-se que "estudava coisas da educação e debatíamos a proposta curricular do estado" (Entrevista com Cármen, 2017).

Trabalhando na região de Campinas, Cármen também começou a atuar no sindicato, segundo ela:

quando eu trabalhava aqui em Campinas, comecei a participar da APEOESP. Porque uma coisa que o meu pai sempre dizia é 'sempre participe do sindicato'; filha de operário, então eu participava do sindicato (Entrevista com Cármen, 2017).

Relata que frequentava as reuniões e todos os movimentos. Nesse período, as discussões giravam sobre questões trabalhistas e, no que se referia à organização da rede, a professora recorda-se das discussões em torno da proposta curricular da rede. Foi então que 
começou seu interesse em realizar cursos promovidos pela APEOESP e pela diretoria de ensino de Campinas.

Na rede estadual, uma das professoras que Cármen conhecia começou a atuar no Centro de Formação Profissional de Nível Médio (CEFAM) ${ }^{2}$. Sabendo da oportunidade, a professora se inscreveu naquele projeto que modificaria significativamente sua relação com a docência.

[...] abre o CEFAM, a Maria Tereza minha amiga vai para lá. [...] Ela já estava fazendo mestrado, se eu não estou enganada, na Unicamp, com o Milton José de Almeida, no ensino de biologia. Quando abriram a segunda turma do CEFAM, precisariam de outro professor, porque entraram quatro turmas por ano. Então, eram nove aulas de matemática no primeiro ano. Eram nove aulas, eram seis em classe e três para desenvolvimento de atividades... Era periodo integral, né? Então era isso. O professor também tinha uma carga integral... Ai foi que a Maria Tereza falou: "faça o projeto", peguei e fiz o projeto para ser professora lá. Tinha seleção para fazer. O Manoel me ajudou com essa coisa de fazer projeto. Eu não tinha ideia disso. Até hoje faço parte da turma de ex-alunos. Muitos, hoje, são professores universitários. Outros, mesmo com mestrado e doutorado, continuam na escola básica. Eles têm conexão com a pesquisa (Entrevista com Cármen, 2017).

Nesse espaço de formação de professores, Cármen começou a se reconhecer como formadora de professores, "aí fui ser professora no CEFAM. Lá, eu começo a perceber que sou formadora de professora" (Entrevista com Cármen, 2017). Em razão dessa nova função, resolveu cursar uma disciplina como aluna especial na graduação do curso de Pedagogia, da Unicamp, intitulada "Didática da Matemática". Lembra-se de que, na ocasião, o professor Sérgio Lorenzato, seu futuro orientador de mestrado, tecia vários questionamentos durante as aulas, para que ela pudesse contar como acontecia na escola. Ele se mostrava entusiasmado com a possibilidade de a professora contar sua experiência para as futuras professoras. Cármen, por sua vez, nesses espaços e no CEFAM também se via engajada em criar vínculos com o ambiente acadêmico. Recorda-se de ter levado as alunas (futuras professoras) ao I Encontro Paulista de Educação Matemática.

Após esses primeiros contatos com o universo da academia na década de 1990, encontrando um sentido para sua experiência como formadora de professores dos Anos Iniciais no CEFAM, Cármen defendeu sua pesquisa de mestrado, no ano de 1995. Naquele estudo, a professora investigou possíveis transformações das representações matemáticas pelas quais passaram os alunos da turma de 1989 do CEFAM/Campinas. Mediante a análise do material de

\footnotetext{
${ }^{2}$ Nesse espaço constituído a partir de 1982, o objetivo era oferecer oportunidade para alunos do ensino médio da rede pública estadual terem habilitação específica para o exercício do magistério na educação infantil e nas quatro séries iniciais do ensino fundamental. Segundo Saviani (2009, p. 147), "apesar dos resultados positivos, foi descontinuado quando seu alcance quantitativo era ainda restrito, não tendo havido também qualquer política para o aproveitamento dos professores formados pelos centros nas redes escolares públicas".
} 
campo (estudo da prática e registro da prática pedagógica dos participantes), notou-se que, a partir dos processos formativos, os estudantes puderam superar mitos, crenças, valores e falsas concepções com relação à Matemática, com vistas a uma transformação na ação pedagógica do futuro professor.

A pesquisa de doutorado de Cármen, por sua vez, teve como objetivo abordar a problemática do ensino de geometria, considerando aspectos epistemológicos e psicopedagógicos. Para isso, foram realizados estudos de episódios de ensino de geometria. Seu foco foi em compreender como o aluno representa e interpreta representações geométricas e como o professor percebe e explora essas representações. $\mathrm{O}$ estudo de caso foi realizado em uma sala de aula de $4 .^{\text {a }}$ série. Sobre essa experiência, destaca que o principal resultado de seu trabalho no CEFAM,

o que me parece que mudou a partir do trabalho que desenvolvemos foi aversão à matemática, a ansiedade contra a aprendizagem da matemática. Então, a minha ideia é sempre tentar entender, desempacotar essa matemática de alguma forma (Entrevista com Cármen, 2017).

Cármen recorda-se que, durante o mestrado e o doutorado: "eu era professora, então não tinha essa coisa formal de academia". Lembra-se do esforço que foi chegar à forma de um trabalho acadêmico e das parcerias que estabeleceu ao longo do processo,

e aí o que acontece? Tínhamos um grupo de estudo, nós fazíamos o grupo, estudávamos a disciplina, discutíamos o projeto, coisas assim (Entrevista com Cármen, 2017).

Logo após a conclusão do doutorado, Cármen deu continuidade ao seu trabalho como formadora de professores. Naquela altura, o CEFAM já havia encerrado suas atividades. Ela, então, passou a atuar concomitante na escola básica, na rede estadual, e em instituições privadas de ensino superior. Da formação continuada, recorda-se que, em geral, os professores

sempre queriam algumas técnicas que dessem conta de entender para sanar as dificuldades que eles observavam nos estudantes. Mas aí, quando os professores entendiam os erros dos estudantes, começavam a pensar nas próprias lacunas e a quererem estudar (Entrevista com Cármen, 2017).

Sobre o retorno à rede estadual, destaca que "eu voltei do doutorado e comecei a olhar os alunos de outra forma, as perguntas de uma outra forma" (Entrevista com Cármen, 2017). Apesar do entusiasmo latente, os incentivos para continuar na sala de aula da rede estadual não foram proporcionais. Cármen precisou entrar na justiça para conseguir $5 \%$ de aumento em seu salário após a conclusão do doutorado.

Após certo tempo de atuação na PUCCamp, a professora ingressou em um concurso numa universidade federal, como professora do Departamento de Metodologia de Ensino. Apesar de a carreira acadêmica não fazer parte inicialmente de seu horizonte, ela se tornou uma 
pesquisadora e formadora atuante, e trabalha há mais de 16 anos, tendo sido uma das percursoras da área de Educação Matemática na instituição. Sobre a pesquisa que realiza atualmente, destaca que

eu acho que eu aprendo sempre, em todos os embates e projetos. Eu tenho espaços de reflexões sobre o trabalho de formador de professor, eu acho que, dentro dessa perspectiva, aprendo bastante (Entrevista com Cármen, 2017).

Analisando seus temas de interesse atuais de pesquisa, tal como narrativas de professores de Matemática dos Anos Iniciais, é possível notar que seu percurso formativo continua presente em seus focos de estudo. A narrativa, não denominada dessa forma à época, como metodologia para a formação do futuro professor, por exemplo, esteve presente em suas práticas desde sua atuação no CEFAM.

Eu sempre trabalhei com a escrita dos estudantes, [...] todo ano eu começava questionando "o que é a matemática para você?", "o que se ensina na escola?", "como é o ensino de matemática?"... Eu perguntava algumas coisas para o aluno que estava ingressando nessas discussões. Essa iniciativa dava um pouco de rumo para eu trabalhar no curso do CEFAM. Numa perspectiva de tentar quebrar aquelas visões, vamos dizer, pessimistas em relação à matemática, mudar um pouco isso, fazer com que ele saisse diferente. Eu trabalhava com essa escrita, sem pretensão de chamar de narrativa ou de falar de discurso (Entrevista com Cármen, 2017).

A entrevista foi sendo finalizada, com alguns destaques sobre as relações de gênero na Universidade. Cármen ressaltou que a coordenação da pós-graduação está sendo liderada por mulheres há alguns anos. Nota certos conservadorismos em alguns setores e cursos, em específico, que historicamente possuem um percentual reduzido de mulheres.

Desde seu ingresso em uma Universidade Federal, há 16 anos, Cármen tem realizado pesquisas que envolvem professores da escola no grupo de pesquisa que coordena na Faculdade de Educação. Atualmente, o projeto pelo qual é a principal responsável envolve a produção de narrativas no exercício da docência e na formação inicial, em suas dimensões sociais no ensino e na aprendizagem da Matemática nos Anos Iniciais. Os objetivos da pesquisa incluem a integração da universidade com a escola da Educação Básica nas discussões, nas problematizações e no desenvolvimento de projetos que possibilitem, ao mesmo tempo, a formação inicial dos graduandos da universidade e continuada dos professores das escolas. Para isso, os participantes investigam, a partir da produção de narrativas, aspectos que emergem da participação de professores e graduandos em grupos de estudo com características colaborativas, relacionados ao seu desenvolvimento profissional.

A pesquisa realizada entre 2014 e 2018, que precedeu a anterior, aqui citada, teve como foco a Educação Matemática nos Anos Iniciais, a constituição de tarefas exploratórioinvestigativas no contexto do uso das tecnologias. Esse projeto tomou a tecnologia informática 
como mais um componente na formação inicial e/ou continuada de professores dos Anos Iniciais. Nele, buscou-se investigar quais saberes docentes, reflexões e conflitos foram produzidos por um grupo de professores dos Anos Iniciais envolvidos num processo simultâneo de aprender Matemática através de tecnologia informática e de tentar ensiná-la. A pesquisa colaborativa foi a metodologia empregada, uma vez que ocorreu a parceria entre todos os participantes do grupo, ao analisar, estudar e produzir tarefas de caráter exploratórioinvestigativo com uso do recurso tecnológico. Os momentos de preparação das tarefas e os da sua implementação na escola foram videogravados. Também foram produzidas narrativas de formação e de análise dos episódios de ensino.

\section{Considerações sobre as narrativas produzidas}

Retomando alguns questionamentos: quais são os modos de mobilização de insubordinação criativa de educadoras matemáticas ao longo de suas trajetórias? Como posturas de insubordinação criativa culminam em uma pesquisa com profícuas proximidades com o ambiente escolar?

Sabemos que posturas insubordinadas estão relacionadas às crenças que mobilizamos em nosso trabalho diário, conectando-se a um tipo de conhecimento profissional construído ao longo de nossas carreiras (D’AMBROSIO; LOPES, 2015a, p. 06). Tal conhecimento "envolve elementos como origem social, política e cultural, bem como aspectos de foro pessoal e contextual". Em síntese, segundo as autoras, via de regra "o professor e o pesquisador se deparam com uma estrutura escolar ou universitária imersa em profundo controle burocrático e tecnocrático, limitante e condicionante da ação educativa e investigativa" (D’AMBROSIO; LOPES, 2015a, p. 06). No entanto, o trabalho colaborativo tem se mostrado uma possibilidade de projeção de uma postura de insubordinação criativa que envolve profissionais da Universidade e da escola. Como a professora Cármen destaca, à medida que participa de projetos em colaboração com a escola, "eu acho que eu aprendo sempre, em todos os embates e projetos" (Entrevista com Cármen, 2017).

Mediante análise das narrativas e os indícios de posturas de insubordinação criativa que as protagonistas constituem, é possível vislumbrar que tais mulheres, educadoras matemáticas, optam pela realização de pesquisas conectadas ao cotidiano escolar, ambiente privilegiado de suas formações e, portanto, assumem posturas de insubordinação criativas. Isto

significa dizer que, apesar das pressões institucionais, pelo acúmulo de produções que prejudicam o desenvolvimento de pesquisas a longo ou médio prazo em contextos diversos, as 
protagonistas deste estudo continuamente produzem um tipo de pesquisa, de médio a longo prazo, relacionada à escola, que tem transformado o campo científico e profissional da educação e do professor que ensina Matemática.

Em síntese, as pesquisas realizadas por Regina e Cármen não se enquadrariam na perspectiva de processo-produto (COCHRAN-SMITH; LYTLE, 1990). Também não podem ser consideradas do tipo qualitativo ou interpretativo, pois não se trata de uma descrição detalhada do que ocorre na escola. Consideramos os trabalhos e os projetos de Regina e Cármen como insubordinados e criativos, pois envolvem construções de narrativas do cotidiano escolar pelos próprios protagonistas da escola. Podemos considerar que Regina e Cármen conformam espaços para que professores e pesquisadores possam narrar, descrever e analisar as práticas escolares no contexto do ensino e da aprendizagem de Matemática. Esse movimento de autoria do professor atuante na escola compõe práticas colaborativas entre universidade e escola que também podemos relacionar à insubordinação criativa. Sabemos, ainda, que, à medida que estabelecem parcerias, as professoras têm construído em colaboração com colegas e professores novas perspectivas de ensino e aprendizado em Matemática. Nos quatro projetos citados, as pesquisas das entrevistadas avançam em conexão com a escola, do mesmo modo que as pesquisas do campo do professor que ensina Matemática (FIORENTINI; PASSOS; LIMA, 2017).

Mesmo no CEFAM, Cármen já conseguia mobilizar o grupo de futuros professores para que pudessem compreender os erros dos estudantes, conforme destacou: "quando os professores entendiam os erros dos estudantes, começavam a pensar nas próprias lacunas e a quererem estudar" (Entrevista com Cármen, 2017). Regina, por sua vez, como coordenadora de área na escola padrão, aderiu à ideia de planejar aulas de modo colaborativo. Ou seja, elas já adotavam práticas colaborativas muito antes de esse conceito ser discutido nos meios acadêmicos.

Outro aspecto importante das atuações de Cármen e Regina refere-se à insubordinação a um tipo de formação ainda muito frequente no Brasil. Sabemos que em nosso país, desde a implantação das reformas neoliberais em meados dos anos 80, a educação tem sido concebida como um grande e promissor negócio (ZEICHNER; DINIZ-PEREIRA, 2005). Muitos pacotes prontos chegam à escola. Nesses contextos, a formação docente ocorre em cursos de preparação inicial, geralmente baseados em modelos da racionalidade técnica e, quando existentes, os programas de formação continuada são normalmente centrados em cursos teóricos e de curta duração (ZEICHNER; DINIZ-PEREIRA, 2005).

Ao desenvolverem projetos de duração mediana, cerca de dois a quatro anos, 
desenvolvendo o uso das narrativas sobre o cotidiano escolar, valorizando as diversas experiências e significações trazidas pelos professores, Cármen e Regina implementam processos formativos atualizados com as novas perspectivas de formação continuada de professores. O uso da metodologia de análise de vídeos traz o adicional de avançar nas constatações do modo como reverberam nas escolas as formações e o desenvolvimento profissional que ocorrem em grupos colaborativos. Destaca-se que o trabalho com análises de vídeos desenvolvido pelas pesquisas se inicia antes mesmo da chegada mais acentuada das pesquisas com Lesson Study ao Brasil. O modo como se dá a formação dos professores envolvidos no projeto também faz frente à racionalidade técnica.

\section{6 À guisa de concluir}

Historicamente, como destacamos com base em Cochran-Smith e Lytle (1990), os dois tipos de pesquisas predominantes em educação eram processo-produto ou qualitativointerpretativo. Em ambos os casos eram as vozes, as perguntas, as percepções e, sobretudo, as conclusões dos pesquisadores que sintetizavam o vivido no ambiente escolar. Sabemos que essas pesquisas ainda perduram, mas, a cada dia, convivemos com a pesquisa do professor que atua na sala de aula, uma vez que professores da escola básica ocupam ou coexistem no espaço de criação, autoria e voz dos pesquisadores. Não há como negar que indícios de insubordinação criativa surgem a partir dessa pesquisa que se inicia com perguntas advindas do ambiente escolar. As trajetórias das protagonistas deste estudo levam a essa movimentação.

A partir da resistência a um tipo de pesquisa e a um tipo de formação desarticulada da realidade escolar, as educadoras participantes da pesquisa constituíram posturas de insubordinação criativa. Em uma análise das narrativas produzidas, é possível vislumbrar que tais mulheres, ao desenvolverem estudos conectados à prática letiva, constituem posturas de contínua interrogação e produção de um tipo de pesquisa, relacionada ao cotidiano escolar, que tem transformado o campo científico e profissional da educação e do professor que ensina matemática. O espaço de autoria é algo dado ao professor que está na escola. As perguntas não são provenientes dos acadêmicos, mas negociadas em colaboração com os participantes dos projetos.

Essas mulheres são professoras que ensinam Matemática e, por essa razão, constituemse educadoras matemáticas mediante a participação e a criação de contextos de pesquisa e de programas de formação de professores inicial e continuada. A pesquisa se tornou um caminho necessário na vida delas, a partir de práticas constituídas em contextos escolares e/ou de 
formação de professores. Elas são professoras e se tornam pesquisadoras, à medida que questões emergentes da prática as instigam.

\section{Referências}

CLANDININ, D. J.; HUBER, J. Narrative inquiry. In: MCGAW, B.; BAKER, E.; PETERSON, P. P. (Ed.). International encyclopedia of education.3. ed. New York: Elsevier, 2010. p. 436-441.

CLANDININ, D. J.; CONNELLY, F. M. Pesquisa narrativa: experiência e história em pesquisa qualitativa. Tradução: Grupo de Pesquisa Narrativa e Educação de Professores ILEEI/UFU. Uberlândia: EDUFU, 2011.

COCHRAN-SMITH; LYTLE, S. Research on teaching and teacher research: the issues that divide. Educational Research, London, v. 19, n. 2, p. 2-11, 1990.

COCHRAN-SMITH, M.; LYTLE, S. L. Inside/outside: Teacher research and knowledge. New York: Teachers College Press, 1993.

D’AMBROSIO, B. S.; LOPES, C. E. Modos de uma Professora de Matemática Narrar as suas Ações de Insubordinação Criativa. In: CONGRESSO INTERNACIONAL DE PESQUISA (AUTO)BIOGRÁFICA (VI CIPA), 6., 2014, Rio de Janeiro. Anais... Rio de Janeiro: UERJ, 2014. v. 1.

D'AMBROSIO, B. S.; LOPES, C. E. Insubordinação Criativa: um convite à reinvenção do educador matemático. Bolema, Rio Claro, v. 29, n. 51, p. 1-17, apr. 2015a.

D'AMBROSIO, B. S.; LOPES, C. E. Insubordinação criativa de educadoras matemáticas evidenciadas em suas narrativas. In: CONFERÊNCIA INTERAMERICANA DE EDUCAÇÃO MATEMÁTICA, 14. 2015, Tuha. Anais. Tuxtla Gutiérrez, 2015 b.

FIORENTINI, D.; LORENZATO, S. Investigação em Educação Matemática: percursos teóricos e metodológicos. Campinas: Autores Associados, 2006.

FIORENTINI, D.; PASSOS, C. L. B.; LIMA, R. C. R. Mapeamento da pesquisa acadêmica brasileira sobre o professor que ensina Matemática: Período 2001 a 2012.Campinas: FE-Unicamp, 2017. v. 1. $488 \mathrm{p}$.

SAVIANI, D. Formação de professores: aspectos históricos e teóricos do problema no contexto brasileiro. Revista Brasileira de Educação, Rio de Janeiro, v. 14, n. 40, p. 143-155, apr. 2009. Disponíevel em: http://www.scielo.br/scielo.php?script=sci_arttext\&pid=S141324782009000100012\&lng=en\&nrm=iso. Acesso em: 31 jan. 2019.

ZEICHNER, K. M.; PEREIRA, J. E. D. Pesquisa dos educadores e formação docente voltada para a transformação social. Cadernos de pesquisa, São Paulo, v. 35, n. 125, p. 63-80, 2005.

Submetido em 27 de Julho de 2018. Aprovado em 18 de Junho de 2019. 